\section{The Impact of Horticultural Responsibility on Health Indicators and Quality of Life in Assisted Living}

\author{
Claudia C. Collins ${ }^{1,3}$ and Angela M. O’Callaghan ${ }^{2}$
}

ADDITIONAL INDEX WORDS. mastery, self-rated health, quality of life, horticultural therapy, people-plant interactions, human issues in horticulture, mind-body interaction

SUMMARY. This study used quantitative and qualitative methods to investigate the impact of indoor gardening on elderly residents of a low-income assisted living facility over a 4-week period. Mastery, self-rated health, and self-rated happiness were pre-, post-, and post-post measured to evaluate whether a short-term introduction of indoor gardening that involved individual plant-care responsibility would improve these measures that are predictive of health and quality of life. Eighteen residents participated in four 2-hour interactive horticulture classes taught by a social horticulturist and a sociologist. Class members showed a significant increase in mastery, self-rated health, and self-rated happiness. The results of this study indicate that a basic horticultural activity, as simple as learning how to maintain a houseplant and taking individual responsibility for one, can have a short-term positive impact on the quality of life and on primary indicators of future health outcomes of older adults residing in assisted living facilities.

$\mathrm{D}$ uring the last century, the average American lifespan has almost doubled as people live longer, stay healthier, and remain active. Between 2000 and 2030, the U.S. population aged 65 years and older is expected to double to more than 71 million (U.S. Department of Health and Human Services, 2006). Seventy-eight million "baby boomers" will begin turning 65 years old in 2011, at an average of 10,000 per day.

As the population ages, the number of people moving from their homes to assisted living or long-term care facilities will increase dramatically. This residential shift requires an examination of the quality of life for the older adults who will reside in those facilities.

Mastery and self-rated health (SRH) have been found to be two of the most accurate predictors of the social concept of "successful aging." Successful aging is defined as high mental and physical functioning, and active engagement with life (Rowe and Kahn, 1998). A large body of research has repeatedly found mastery and SRH to be leading and

${ }^{1}$ Associate Professor, Aging Issues, University of Nevada Cooperative Extension, Las Vegas, NV 89123

${ }^{2}$ Associate Professor, Social Horticulture, University of Nevada Cooperative Extension, Las Vegas, NV 89123

${ }^{3}$ Corresponding author. E-mail: collinsc@unce.unr.edu. accurate indicators of future health outcomes, predictive of enhanced recovery from illness (Berkman et al., 1992), decreased use of health services such as hospitalization (Kennedy et al., 2001) and nursing home admission (Freedman, 1993), lessened depression (Jang et al., 2002), and lower mortality rates (Surtees et al., 2006). This research has demonstrated that mastery and SRH are strong indicators of present and future health as well as quality of life for older adults.

Mastery is the belief that one's actions and choices determine outcomes in their life (Mirowsky and Ross, 1990). Mastery can, but does not have to, decrease with age, especially in women (Ross and Mirowsky, 2002) and the disabled (Schieman and Turner, 1998). Evidence of the mind-body connection is demonstrated when research finds that a stronger sense of mastery and higher estimates of SRH are better predictors of future physician-assessed health (Mossey and Shapiro, 1982; Surtees et al., 2006).

Assisted living facilities (ALFs) are a relatively new and growing elder-housing phenomenon. This residential option gives the elderly a way to age-in-place, to maintain their independence and functionality, providing a bridge between their own home and a nursing home. Moving health outcomes and mortality than from their own home into the communal living of an ALF is a major life change, often a result of declining health or the death of a spouse (Hawes et al., 1999). Mental and physical health may decline for seniors required to move to a new environment (Hays, 2002). These lifetransition facilities require major adjustments for most elders who can experience disruptions of their perceived well-being, creating a unique teaching opportunity for interventions designed to improve success of the transition process (Collins and O'Callaghan, 2007). However, little work has been done to create transitional education for assisted living residents.

The idea of horticultural benefits for older adults is not new and has been researched by social scientists as well as horticulturists. In the 1970s, two Yale psychologists examined the value of people-plant interactions in a Connecticut nursing home (Langer and Rodin, 1976). They found enhanced personal responsibility and choice between groups that were responsible for plant care compared with those who had staff care for their plants. Those who cared for their own plants were more alert, and interacted more with fellow residents and staff while requiring less staff care. They self-reported being active and happy (self-rated happiness) with increased perceptions of personal control. This small intervention showed dramatic results in an environment where decision-making otherwise seemed to be nonexistent. Other studies of nursing homes in the 1970s found active therapies such as gardening had benefits reflected in measures of life satisfaction and self-esteem (Willcox and Mattson, 1979).

The area of older adults and the relationship of responsibility to mastery, and SRH and self-rated happiness is a new exploration in the vulnerable assisted living population. One known way to improve the physical or emotional status of people who have diminished control over their lives is by encouraging them to take responsibility for another individual. This "other individual" may be animal or plant. There is little, if any, published research measuring responsibility in the assisted living population, or for low-income residents of these facilities. However, 
there is some data on the positive impact of personal responsibility with animal care in prisons and plant care in nursing homes. For instance, if they have had responsibility for animals while in prison, most inmates do not re-offend after release (Strimple, 2003). This reflects very positively in comparison with the national average for released inmates, over two-thirds of whom are re-incarcerated within 3 years (U.S. Department of Justice, 2002). In studies with the elderly, hands-on experience with plants was found to have a greater effect than passive observation of plants. As seen above in the 1970s study (Langer and Rodin, 1976) and also a more recent study of assisted living guidelines (Regnier, 2003), active interaction with plants and other residents is desired and beneficial.

Horticulture and gardening have been shown to benefit institutionalized populations. Research has demonstrated that seriously ill hospital patients and infirm elderly patients showed improved health outcomes when they were exposed to living plants. Facilities that work with elderly populations have begun using garden sites in their landscapes and as part of their therapeutic interventions (Barnicle and Midden, 2003; Bassen and Baltazar, 1997; Rappe and Kivela, 2005). These efforts take many forms from passive enjoyment to active group activities such as growing plants or produce, which research has demonstrated to enhance emotional health and participant involvement in older adults (Browne, 1992; Kweon et al., 1998; Predney and Relf, 2004).

Gardening is an activity that has been enjoyed by many older adults. The majority ( $90 \%$ ) of nursing home residents surveyed in an Illinois study reported that they had enjoyed gardening in their past. Many expressed regret that leaving their homes would end their gardening activities (Rothert and Daubert, 1981).

Most ALFs have an activity director who surveys incoming residents to determine leisure interests. McGuire (1997) found that many senior care facility residents had previously engaged in some form of gardening, indicating that they might be receptive to participation in some form of horticulture activity.
Research has been conducted on residents of nursing homes and the new counterpart, long-term care centers. On the other hand, little research has been conducted on assisted living residents, especially a low-income population, because assisted living is a relatively recent housing option and these facilities for the low-income population are rare. Assisted living differs from nursing homes, housing a different population that tends to be more mobile and independent. ALFs focus on resident privacy in their own apartments and autonomy presented in a homelike atmosphere (Frank, 2002). Residents' lives involve more decision making, such as selecting the time of their meal service, ordering from a menu, choosing whether to participate in multiple activities and deciding how to decorate their private apartments. Moving to assisted living represents a crucial time when seniors decide whether to enjoy their own apartments in a safe and supportive environment with congregate meals or look at the move as an endof-life place or "the old-folks home." This creates a need to measure the effect of taking personal responsibility in this population.

The Silver Sky Project is Nevada's first affordable, nonprofit assisted living center with 90 accessible/ adaptable apartments. The 5-acre (2.0 ha) campus is located in an upscale community. Assisted living is costly, with monthly fees ranging from $\$ 3000$ to more than $\$ 5000$. Silver Sky residents pay $\approx 20 \%$ to $50 \%$ of that for a one-bedroom apartment in a luxurious facility. In its first year of operation, staff and management found that the low-income residents tended to require yet another level of care. They appeared to have more needs than many assisted living residents, although not requiring the skilled healthcare of a nursing home or long-term care center.

One instructor began teaching wellness classes in 2006, just after Silver Sky opened. She was disappointed by low resident participation. Residents had limited involvement with all the activities offered, even the old standbys of bingo and playing cards. The Silver Sky director and activity director felt "they are just not interested."

Residents did not seem to view assisted living as a choice but rather as their only option. They did not feel it was a new neighborhood with new neighbors. While working to develop an outdoor healing garden for Silver Sky, it became obvious that an interim step was needed. Social interaction in ALFs has been found to be predictive of quality of life and measures of happiness (Street et al., 2007). Theorizing that plants could make the residences feel "more like home," this indoor gardening project was created.

The main question in this research was: What effect would a short-term horticulture program have on the psychological well-being of people in a low-income ALF? The purpose of this study was to measure the short-term impact of a 4 -week interactive plant class to describe and measure the relationship between responsibility for a plant and sense of mastery, SRH, and self-rated happiness among low-income assisted living residents. It was hypothesized that the process of having responsibility for a plant might improve participants' sense of mastery, and the related area of SRH and their selfrated happiness, all of which are indicators of future health outcomes, sense of well-being, and quality of life.

\section{Subjects}

All study participants actively chose to participate in the plant class. The class was advertised in the monthly resident newsletter and one instructor made a presentation to lunch groups a week before the classes started. On the day of the first class, the instructor and activity director reminded residents that the class would immediately follow the second lunch seating.

Each of the 18 participants was in a wheelchair or used a walker. Background information gathered on participants included their age, gender, ethnicity, and educational level (Table 1). The age range was from 75 to 102 years $($ mean $=85.17$ years $)$. Sixteen were women, two were men. All met low-income standards to qualify for residence. They were asked about their skill level with plants (very experienced, experienced, very little experience, or none), their prior gardening experience (indoor, outdoor, both, or neither) and whether this gardening experience took place in Nevada. 
Table 1. Background characteristics and demographics of residents of an assisted living facility that participated in a 4 -week plant care class. This also measures their reported experience with plant care and gardening.

\begin{tabular}{|c|c|}
\hline $\begin{array}{l}\text { Background } \\
\text { characteristics } \\
\text { and demographics }\end{array}$ & $\begin{array}{c}\text { Students } \\
\text { (no.) }\end{array}$ \\
\hline \multicolumn{2}{|l|}{ Ethnicity } \\
\hline Caucasian & 14 \\
\hline African American & 2 \\
\hline Asian & 1 \\
\hline Native American & 1 \\
\hline \multicolumn{2}{|l|}{ Education level } \\
\hline Not completed high school & 3 \\
\hline High school graduate & 8 \\
\hline College or graduate school & 7 \\
\hline \multicolumn{2}{|l|}{ Gardening experience ${ }^{\mathrm{z}}$} \\
\hline None & 2 \\
\hline Little & 7 \\
\hline $\begin{array}{l}\text { Experienced or very } \\
\text { experienced }\end{array}$ & 9 \\
\hline
\end{tabular}

Many expressed interest in the class because of prior experience with indoor or outdoor gardening and some chose to participate because they enjoyed a health promotion program conducted 6 months previously (to a much smaller group). These were dedicated participants; over the 4-week period, no subjects missed a class. Some even rescheduled doctors' appointments and delayed family visits to attend each class. At the fourth class, the students expressed dismay that the class would not continue. They were reminded that they would be the "founding members" of the outdoor healing garden. They would also have the option to be trained as University of Nevada Cooperative Extension (UNCE) Master Gardeners and serve as teachers for their fellow residents.

\section{Methods}

This study was conducted over a 4-week time period in Sept. 2007. Quantitative data were collected using Pearlin and Schooler's mastery scale with construct validity confirmed (Pearlin et al., 1981) and individual questions regarding $\mathrm{SRH}$ and self-rated happiness.

The mastery scale consists of seven items (Table 2) to which the
Table 2. Survey questions that were used in written format in the first and last plant classes to determine participants' levels of mastery, self-rated health, and self-rated happiness.

\begin{tabular}{lc}
$\begin{array}{l}\text { Question } \\
\text { no. }\end{array}$ & Survey question \\
\hline 1 & $\begin{array}{c}\text { What happens to me in the } \\
\text { future mostly depends on me } \\
\text { Sometimes I feel that I am } \\
\text { being pushed around in life }\end{array}$ \\
3 & $\begin{array}{c}\text { I have little control over the } \\
\text { things that happen to me }\end{array}$ \\
4 & $\begin{array}{c}\text { There is really no way I can } \\
\text { solve some of the } \\
\text { problems I have }\end{array}$ \\
5 & $\begin{array}{c}\text { There is little I can do } \\
\text { to change many of the }\end{array}$ \\
& important things in my life \\
6 & I often feel helpless in dealing \\
& with the problems of life \\
7 & I can do just about anything \\
8 & I really set my mind to do \\
& How would you rate \\
9 & your health? \\
& How would you rate your \\
& happiness?
\end{tabular}

$\overline{{ }^{2} \text { Questions } 1 \text { through } 7 \text { measure mastery (Pearlin }}$ et al., 1981). Choices for responses were: strongly agree, agree, neither agree nor disagree, disagree, or strongly disagree. Strong agreement was graded 1 and ranged to 5 for strong disagreement for questions 1 and 7 . For questions 2 through 6 , strong agreement was 5 and strong disagreement was graded 1. Question 8 measured self-rated health and question 9 measured self-rated happiness. These two were rated on a scale from 1 (lowest) to 5 (highest).

respondents used a five-point Likert scale to indicate their level of agreement with the items. For questions 1 and 7 , the scale ranged from 1 (strongly agree) to 5 (strongly disagree). Negatively worded items (questions 2-6) such as "I have little control over what happens to me" or "Sometimes I feel like I'm being pushed around in life" would be reverse-coded during analysis. The level of mastery was obtained by summing all responses to obtain a mastery score. In any one item, 5 indicated the highest level of mastery and 1 the lowest; thus, scores could range from 7 (low mastery) to 35 (high mastery).

Thousands of published studies have used the mastery scale and this measure has been used extensively on the aging population. The scale has been used for more than a decade on an independent-living elder population $(\mathrm{N}>1000)$ participating in a longer-term wellness program (Collins and Benedict, 2006). And recently, this seven-item scale, along with $\mathrm{SRH}$, was used to establish a baseline measure of the statewide elder population in Nevada $(\mathrm{N}=$ 2626 in 2006 and $\mathrm{N}=2434$ in 2007). For those larger studies, the reliability of the measurement was determined by calculating Cronbach's alpha coefficients, which was high $(\alpha=0.806)$. For the population of this study, the Cronbach's alpha measure of internal consistency was also high $(\alpha=0.76)$.

SRH and self-rated happiness were each measured with one standardized question. The SRH question, "How would you rate your health?" has been used in many medical and social research studies measured with a four-point Likert scale that is coded $(\mathrm{l}=$ excellent health, $2=$ good health, $3=$ fair health, and $4=$ poor health). Although less work on the aging population and the predictability of self-rated happiness has been done, the authors address it in this study as a preliminary exploration in the area of relationship with responsibility and horticulture. Self-rated happiness was measured with the question, "How would you rate your happiness?" also measured by a four-point Likert scale $(1=$ very happy, 2 = happy, $3=$ sad, and $4=$ very sad .

Participants completed the scales at the beginning of the first class and at the end of the fourth class. Ten of the 18 participants needed assistance (e.g., reading the questions to them and filling out the data forms) because of vision, hearing, or other disability issues. A post-post test was conducted 5 months after the last class. Only eight of the original participants were available to post-post test in a follow-up class. Three participants no longer resided in the facility, two had returned to independent living, and one died. Seven were out of the ALF that day for a variety of other commitments that included vacation, doctor visits, and outings with family members.

The qualitative data for this study was collected by interviews and by observation. The two instructors and two teaching assistants recorded their observations, including direct quotes, after each session. The interviews were conducted in Sept. 
and Oct. 2007 by the authors at the ALF at the end of the 4-week class sessions. The average duration of the interviews was $1 \mathrm{~h}$. Information was requested on what they thought about the class, how their life had changed or been impacted, what they thought they had learned, and how they felt about their plants. (See Table 3 for list of interview questions, with some possible prompt questions suggested, if necessary, to elicit answers).

\section{Horticulture activities}

The horticulture class took place in an indoor activities room at tables where residents could sit on chairs or in their wheelchairs. The tables were pushed together in a horseshoe format so that the instructors were in the middle and each participant could see and hear the instructors and each other. This format tends to discourage side conversations that disturb the group process. The authors conducted the 2 -h interactive horticulture classes with assistance in data gathering, planting, and transport by two teaching assistants.
WEEK 1. Introductions, quantitative testing, and evaluation of their plant skills were conducted. Testing was complicated in that four had hearing problems and six students had vision problems and needed to have the scales read to them individually. Thus, 10 were individually tested.

As a class activity, each student was asked about their personal plant desires (flowering, easy to care for, herbs, etc.). Some were specific such as plant type [e.g., african violet (Saintpaulia)], smell, etc. They described the lighting situation in their own apartment (morning light, afternoon light, not much light, etc.). This opportunity was used to explain which plants on their preference list would match the lighting conditions in their apartment. This sent an important message to each student that they were an individual with unique circumstances, and that the class would as much as possible meet their specific needs.

WEEK 2. Students were instructed in the basics of houseplants, such as transplanting and care. Each student selected his or her own plant

Table 3. Qualitative open-ended questions that were used by interviewers to promote discussion about the participants' lives, recent changes in their lives, and the impact of the plant classes. The first group of questions was asked before classes started and in the first class, and the second group of questions was asked up to 4 weeks after the last class. This form was seen only by the interviewer, and items in parentheses were there only to stimulate discussion, if necessary.

\begin{tabular}{ll}
\hline Question no. & Survey question \\
\hline & Before class and in early classes \\
& What is your previous experience with plants \\
& (extensive, limited, none)? \\
& What was the nature of your experience \\
3 & (interior, exterior, desert or other region)? \\
4 & How do you feel about your current (new) \\
5 & living situation (assisted living)? \\
& Where did you move from? \\
1 & What changes have you had to make in this new \\
2 & living situation (positive and negative)? \\
3 & After the last class \\
4 & How do you feel about plants now? \\
5 & How do you interact with your plants? \\
6 & What has changed in your interaction? \\
7 & How did you feel about the class and the experience? \\
8 & What did you learn? \\
9 & What did you like? \\
10 & What did you dislike? \\
11 & What could be changed or added in future classes? \\
& How did the plants affect your life? \\
\hline & What changes, if any, have you made in your life \\
& because of the plants or the class? \\
& Since a plant is responsibility, how do you \\
& feel about that?
\end{tabular}

to transplant and maintain in their own apartment. At first, participants were given plastic pots but when a UNCE teaching assistant went out to purchase additional supplies, she found a sale at a discount store and returned with decorative ceramic pots. Faces in the class lit up when they saw this option. Each had already selected a plant but had not started transplanting. At the end of the class, they were asked to bring their plant back to the next class.

Parenthetically, this process of plant transport was extremely labor intensive because all participants were in a wheelchair or walker. They juggled the plants in their laps, in wheelchairs, and on their walkers. Two professors, two teaching assistants, the facility activity director, and a custodial staff member were all needed to keep the program running smoothly. The residents also enjoyed the opportunity to have an instructor visit their apartment.

WeEk 3. Each person brought back his or her plant and proudly reported about the successes/problems with the plants and asked questions. After getting feedback and interacting with their peers, each was allowed to select an herb to plant and care for in his or her apartment. Some chose seeds, whereas others transplanted small herb plants based upon their personal preferences.

WeEK 4. Students had been asked to bring back only their herb plants or seedlings, but all opted to also bring their plants again. The class then discussed their herb plant experiences over the previous week. They asked questions about watering, light, and herb uses. They described actions that worked for them individually and were proud to hear their individual experiences validated by the instructors and their peers. Near the end of the last class, each participant was asked to share with the others what he or she gained from the class.

\section{Results and discussion}

Quantitative. The three scales were analyzed using paired $t$ tests to determine if there were significant differences in scores from pre-class (tl) to post-test at the end of the 4week class ( $\mathrm{t} 2$ ) and also the post-post testing 5 months later $(\mathrm{t} 3)$. The analyses were performed separately in the 
three areas: mastery (Table 4), SRH (Table 5), and happiness (Table 6).

The horticulture program participants significantly increased their scores on all three measures from pre $(\mathrm{tl})$ to post $(\mathrm{t} 2)$. The most significant increase came in mastery and $\mathrm{SRH}$, as it did in the comparison between pre ( $\mathrm{tl}$ ) and post-post ( $\mathrm{t} 3)$. Happiness also increased, but at a lower level of significance. When comparing the post-testing ( $\mathrm{t} 2)$ to post-post testing ( $\mathrm{t} 3), \mathrm{SRH}$ was more significant than mastery or happiness. (Tables 4, 5, and 6).

Each of the seven individual mastery items was analyzed for mean responses (Fig. 1).

Questions 1, 2, 6, and 7 demonstrated statistical differences in mean response between pre- and post-testing intervals. In questions 1 and 7 , there was no statistical difference between post ( $\mathrm{t} 2)$ and post-post ( $\mathrm{t} 3$ ). In all cases, the post-post responses were statistically different from the responses given at the beginning of the program.

The results found here are comparable with findings from a much larger study of a 16-week wellness program for independent-living older adults (Collins, 2006; Collins and Benedict, 2006). However, the quality-of-life enhancements with this horticultural intervention appear to have occurred more quickly, were more dramatic, and clearly reconnected participants to times in their lives when they felt in control.

Qualitative. The qualitative analysis of the responses to the open-ended interview questions (listed in Table 3) was content analysis conducted to determine how the participants described their lives and impact of the plants on their lives. This format allows topics to emerge with frequency of mention without being confined by index word counts. Because it was expected that the qualitative findings might reflect the quantitative test results of a higher sense of mastery, and SRH and selfreported happiness, evidence was sought for changes in life outlook (e.g., if they felt more in control of their lives or what had changed for them) in their lives over the 4 -week period of the intervention.

Table 4. Paired $t$ test of participants' responses to seven questions indicating a sense of personal mastery over their lives (Pearlin et al., 1981) before (tl), immediately after (t2), and 5 months after the horticulture program (t3).

\begin{tabular}{lrccc}
\hline $\begin{array}{l}\text { Time interval } \\
\text { comparison }\end{array}$ & $\mathbf{N}$ & Mean & $\mathbf{t}$ & $\boldsymbol{P}$ \\
\hline Pre- to post $(\mathrm{t} l-\mathrm{t} 2)$ & 18 & -2.39 & -6.75 & 0.001 \\
Pre- to post-post $(\mathrm{t} 1-\mathrm{t} 3)$ & 8 & -5.38 & -4.07 & 0.005 \\
Post- to post-post $(\mathrm{t} 2-\mathrm{t} 3)$ & 8 & -3.13 & -2.0 & 0.086 \\
\hline
\end{tabular}

Table 5. Paired $t$ test of participants' responses to one question indicating their personal evaluation of their health before (t1), immediately after ( 22$)$, and 5 months after the horticulture program (t3).

\begin{tabular}{lrlll}
\hline $\begin{array}{l}\text { Time interval } \\
\text { comparison }\end{array}$ & N & Mean & t & $P$ \\
\hline Pre- to post $(\mathrm{t} l-\mathrm{t} 2)$ & 18 & -0.5 & -4.12 & 0.001 \\
Pre- to post-post $(\mathrm{t} \mathrm{l}-\mathrm{t} 3)$ & 8 & -1.25 & -3.99 & 0.005 \\
Post- to post-post $(\mathrm{t} 2-\mathrm{t} 3)$ & 8 & -0.75 & -3.0 & 0.02 \\
\hline
\end{tabular}

Table 6. Paired $t$ test of participants' responses to one question indicating their personal evaluation of their happiness before (tl), immediately after ( 2 2), and 5 months after the horticulture program $(\mathrm{t} 3)$.

\begin{tabular}{lrccc}
\hline $\begin{array}{l}\text { Time interval } \\
\text { comparison }\end{array}$ & $\mathbf{N}$ & Mean & t & $\boldsymbol{P}$ \\
\hline Pre- to post $(\mathrm{t} l-\mathrm{t} 2)$ & 18 & -0.22 & 2.2 & 0.042 \\
Pre- to post-post $(\mathrm{t} 1-\mathrm{t} 3)$ & 8 & -0.5 & -2.65 & 0.033 \\
Post to post-post $(\mathrm{t} 2-\mathrm{t} 3)$ & 8 & -3.75 & -2.05 & 0.08 \\
\hline
\end{tabular}

Even more impressive than the quantitative score improvements (albeit on a limited number of participants) was the transformation in students' overall demeanor as the classes progressed. They changed from a state of passive, lonely dependence to being more active, socially connected (quality of life), and responsible for something other than themselves (mastery). One example was a woman in her mid-80s who stated at the first class, "I don't even wash my own backside - why would I want to take care of a plant?" Only 20 minutes later, she was laughing and chatting, "This is so much fun!" By the fourth class, she had painted her pot lavender because it contained a lavender plant.

Shortly before the second class started, a woman pushed her mother's wheelchair up to the table near the front of the room. "I just wanted to thank you for this class. My mother has talked about it all week. She hasn't been this interested or this excited about anything for years. Thank you so much." Her mother was impeccably dressed and her blue eyes sparkled with excitement.

Notes taken on class interaction and data from the participant interviews were analyzed. The following key categories emerged and were clustered by rank of topic frequency.

Companionship. One woman said her plant is the "warmest thing in her house ... her buddy." Another was going to name her plant as she saw this plant as a person, a companion. A 96-year-old man stated he would treat the plant, "like a lady and tell it how beautiful it was every day." Several class participants put their name tag from the class on their planter.

Many reported talking or singing to their plants, or playing music for them, i.e., treating the plants like companions. One woman said that she could not wait to talk to her plant because she heard that they liked this and her plant was like a person to her. She had worked with plants in her home and yard before coming to Silver Sky and she was "so excited about this class." Another said that she played classical music to her plants. "I talk to my plants and play them music-they love it and it gives me company. I am not so lonely." One student sang to her plant in Italian, her first language. 


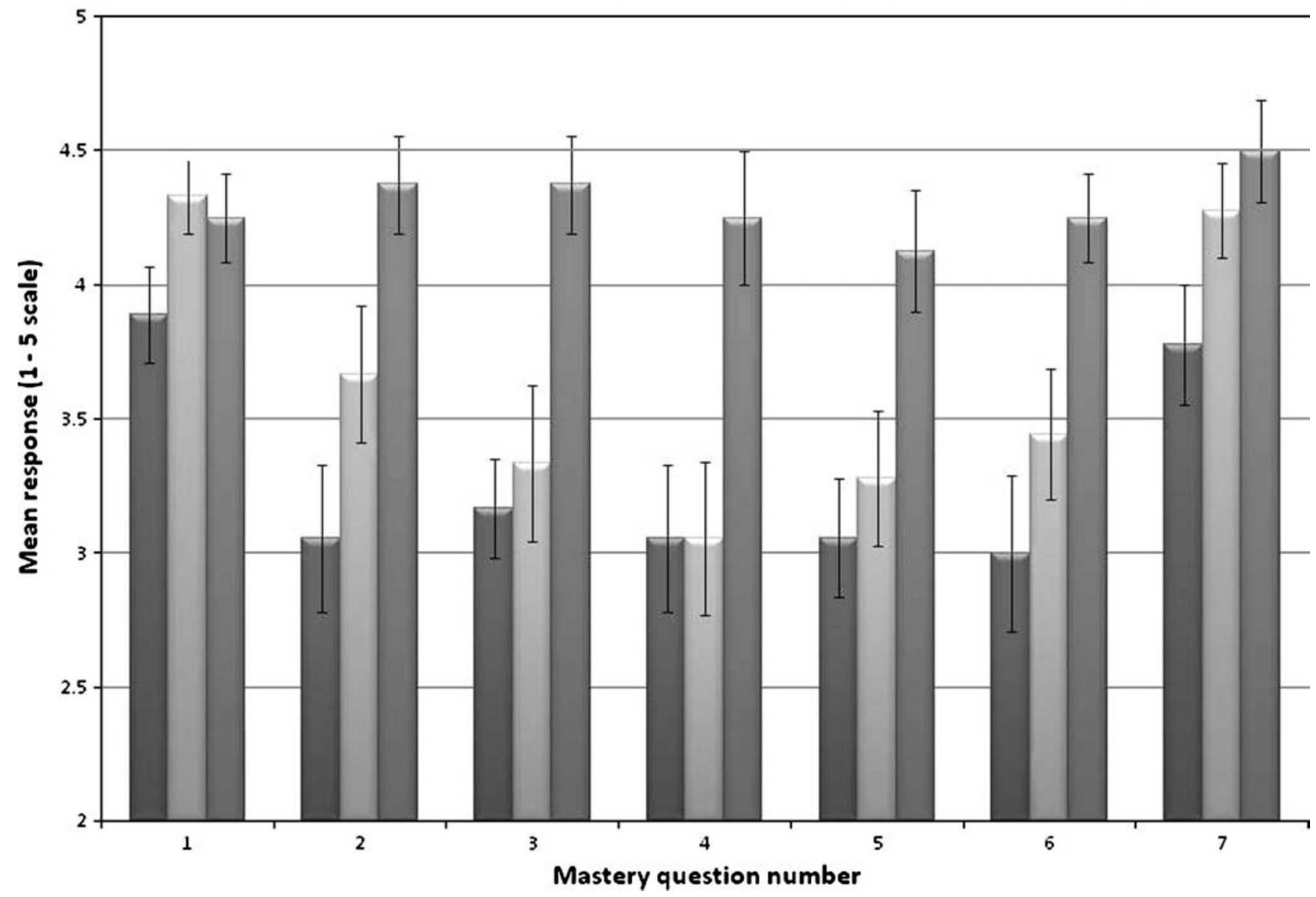

Fig. 1. Comparison of the assisted living horticulture class mean responses to questions indicating individual perception of their control over their lives (Pearlin et al., 1981), before (t1), immediately following (t2), and 5 months after the horticulture program (t3). The seven questions asked are listed in Table 2. Each score can range from 1 to 5; error bars = one SE; $\mathbf{N}=18$ (pre and post); $N=8$ (post-post).

ACtive AND ENERgetic PARTICIPATION. The overall energy was positive and electric as everyone involved could not wait to see how their plants would fare. They tried to decide whether to place it in their window or elsewhere in their apartment. Comments were made such as, "makes you feel good," and "I haven't had anything to take care of in a long time." Attitudes of general excitement, well-being, and something to look forward to were prevalent.

As the class progressed into transplanting, the messy process created a transformation in the participants. Potting soil was everywhere and for many it was the first time in months, or years, that they had not been treated as an invalid. They got dirty hands, dirt on their clothes, and felt "competent." They enjoyed the creative process. Several students commented on how much they loved this class, getting their hands dirty, having a plant to watch and take care of, how it brightened up their apartment and gave them something to do.

The students did not limit their interaction to their plants. Many commented on enjoying this opportunity to learn from each other. One lady stated she waited every week for this class, that she "just could not wait for Mondays to get here so she could come to class!"

For many, the opportunity to garden was a return to their younger, more active days. One woman proudly said she had been "playing with plants" for $60+$ years and was so excited to be back at it! Another said, "I used to garden all the time, but now that I only have half a hand, I can't. I always had plants in my house." One lady was pleased that her dill (Anethum graveolens) seeds sprouted in just 1 week and it brought back memories of growing dill in her home garden. This exercise of planting, plant care, fragrant smells, and sights for many appeared to reconnect them to a happier time in their life.

Students who had no gardening experience expressed satisfaction with learning something new. One woman stated, "I love plants, but I don't know anything about them. I'm learning, though." Another said, "Everything I know about plants I learned in this class, thanks." One man who had never had plants before said how happy he was that his "are surviving!" A retired farmer stated, "If anyone had told me I'd be growing plants in a pot, I'd have called them crazy. I didn't know it could be this easy and fun."

FEel NEeDED. "Waking up in the morning and knowing the plant made it through the night," was a special 
joy for one student. Another took her responsibility seriously, "moving the plant to find the right light means the plant needs you!" A 102-year-young woman said her plants "depend on my smile" each day. They reported learning patience waiting for the plants to flower or seeds to grow. Plant death was expected and replacements were available. However, the issue did not arise in this study.

Success / accomplishment. Fortunately, even in a short-term situation, changes can be seen as healthy plants thrive and some bloom. Several individuals commented they could not believe how well their plants did, that they did not have green thumbs and thought they would die and how great it was to see them actually living. One student commented, "The assisted living can be a dreary place and the plant adds happiness."

Instructors noted that participants showed pride in their plants. They were excited about growing herbs from seeds. Some students left the class with three or four plants. They reported that plant care brought them peace by watching growth and regeneration. They enjoyed learning and sharing with others and said that this class reinforced their prior knowledge about plants.

Planning for the future. The next stage of horticulture at Silver Sky will be the development of a community garden. When discussing this, participants stated, "I can't wait until we can get started in the garden outside" and "I already have my plot picked out!"

OTHER GENERAL OBSERVATIONS. Over the 4-week course of the program, the instructors and ALF staff noted that class members were walking/sitting taller, dressing better, and smiling more. Their entire demeanor improved as they increased their interaction with each other and any other residents who inquired about their plants. This enthusiasm was reflected as they arrived earlier for each class. The first class was scheduled to begin at $1: 15$, but gathering and settling in was a slow process. The instruction started at 1:45 PM. By the third and fourth classes, sessions started promptly at 1:15 PM and several students were in the classroom with their plants before $1 \mathrm{PM}$, anxious to "get started."
This plant class was the largest and most successful group activity at Silver Sky in its first 15 months of operation. The facility director and activity director said they "were amazed" by the number of participants and their consistent participation-no dropouts or missed classes. Both provided positive feedback, commenting that they "could not believe how many were raving about this class." This was by far the most active participation in the time the facility had been open. "We never had involvement in anything like this. It's a miracle!"

Limitations. Frequently, older adults who are willing to participate in a program such as this are lifelong learners who generally score higher in mastery scales (Collins, 2006; Collins and Benedict, 2006). Those who "successfully age" better tend to be attracted to similar activities or educational programs. More research should be done to find ways to attract those who do not fit this description. Anecdotal evidence suggests that they are much more likely to just give up on life, especially in a transition from independent living to supportive housing provided in assisted living and nursing home settings.

The study group was small $(\mathrm{N}=$ 18 ) and the project was conducted over a short 4-week time period, with post-post testing 5 months later $(\mathrm{N}=$ 8 ). This is a pioneering effort to relate the assisted living population to prior research on older adults, related to the role of responsibility, specifically horticultural responsibility, and the health indicators of mastery and SRH and the additional quality of life factor of happiness. This study finds a potentially fertile area of research, and impacts on a new and rapidly growing population. Assisted living is a relatively recent addition to elder population living choices, and low-income options are limited.

\section{Conclusions}

As the population ages and larger numbers of older adults transition from living at home to assisted living, it is important to find ways to optimize this major life transition and enhance quality of life. Assisted living residence provides an opportunity to maintain independence, age in place, and potentially avoid or delay nursing home (long-term care) entry.
These results correlated well with previous research conducted by horticulturists and social scientists since the 1970s that found benefits from active plant care to passive exposure to gardens (Barnicle and Midden, 2003; Bassen and Baltazar, 1997; Browne, 1992; Kweon et al., 1998; Langer and Rodin, 1976; Predney and Relf, 2004; Rappe and Kivela, 2005; Willcox and Mattson, 1979).

The mind-body connection is important because mastery and SRH are reliable predictors of future health outcomes, including mortality (Mossey and Shapiro, 1982; Surtees et al., 2006). SRH, as part of a 14-year Yale University epidemiology and public health study, was significantly predictive of future hospitalization (Kennedy et al., 2001), which is the main route to nursing home admission for the elderly. They found that this single question evaluation accurately predicted future hospitalization. Responses of (excellent or good self-rated health) significantly lowered chances of hospitalization for all causes over the next decade and (fair or poor SRH) accurately predicted multiple hospitalizations, despite their physician's evaluation of their health. It is posited that higher mastery and SRH scores in this study could mean better health outcomes for the plant class participants.

Social interaction in ALFs has been found to be predictive of quality of life and measures of happiness (Street et al., 2007). The theory that plants could make the residences feel "more like home" was upheld by this indoor gardening project.

This study was designed to measure the relationship between responsibility for a plant and sense of mastery, SRH, and self-rated happiness among low-income assisted living residents. It was hypothesized that the process of having responsibility for a plant might improve resident scores on these three measures, which are indicators of future health outcomes, sense of well-being, and quality of life.

The results of this study suggest that a horticulture intervention such as personal plant responsibility may be beneficial over a short-time period. Few, if any studies have been published measuring responsibility in assisted living, and none in 
low-income assisted living, making this a pilot study of the population and responsibility. Similar short-term horticultural activities could be used to help integrate new residents into assisted living. This transitional educational process could help make it feel like their new home, a choice (high mastery) as opposed to being "in a home," which would reflect low feelings of control over life. Such activities may limit feelings of lacking control only for a short duration, but that might just be enough to create a successful transition process to assisted living. Future research will assess longer-term impacts as students from this class transition into the core group for ongoing development of an outdoor healing garden at the site.

\section{Literature cited}

Barnicle, T. and K.S. Midden. 2003. The effects of a horticulture activity program on the psychological well-being of older people in a long-term care facility. HortTechnology 13:81-85.

Bassen, S. and V. Baltazar. 1997. Flowers, flowers everywhere: Creative horticulture programming at the Hebrew Home for the Aged at Riverdale. Geriatr. Nurs. (Minneap.) 18:53-56.

Berkman, L.F., L. Leo-Summers, and R.I. Horwitz. 1992. Emotional support and survival following myocardial infarction: A prospective population-based study of the elderly. Ann. Intern. Med. 117:10031009.

Browne, C.A. 1992. The role of nature for the promotion of well-being of the elderly, p. 75-79. In: D. Relf (ed.). The role of horticulture in human well-being and social development. Timber Press, Portland, OR.

Collins, C. 2006. Seniors CAN: Community-based education to promote independence for older adults. Lifelong Learning Inst. Rev. 1:60-68.

Collins, C. and J. Benedict. 2006. Evaluation of a community-based health promotion program for the elderly: Lessons from Seniors CAN. Amer. J. Health Promot. 21:45-52.

Collins, C. and A. O'Callaghan. 2007. Healing gardens for assisted living: An interdisciplinary approach to health edu- cation. J. Ext.45(6). 28 Feb. 2008 <http://www.joe.org/joe/2007december/iw7.shtml>.

Frank, J.B. 2002. The paradox of aging in place in assisted living. Bergin and Garvey, Westport, CT.

Freedman, V. 1993. Kin and nursing home lengths of stay: A backward recurrence time approach. J. Health Soc. Behav. 34:138-152.

Hawes, C., M. Rose, and C. Phillips. 1999. Managing decline in assisted living: The key to aging in place. J. Gerontol. Social Sci. 59B:S202-S212.

Hays, J.C. 2002. Living arrangements and health status in later life: A review of recent literature. Public Health Nurs. 19:136-151.

Jang, Y., W.E. Haley, B.J. Small, and J.A. Mortimer. 2002. The role of mastery and social resources in the association between disability and depression in later life. Gerontologist 42:807-813.

Kennedy, B.S., S.V. Kasl, and V. Vaccarino. 2001. Repeated hospitalizations and self-rated health among the elderly: A multivariate failure time analysis. Amer. J. Epidemiol. 153:232-241.

Kweon, B., W.C. Sullivan, and A.R. Riley. 1998. Green common spaces and the social integration of inner-city older adults. Environ. Behav. 30:832858 .

Langer, E.J. and J. Rodin. 1976. The effects of choice and enhanced personal responsibility for the aged: A field experiment in an institutional setting. J. Pers. Soc. Psychol. 34:191-198.

McGuire, D.L. 1997. Implementing horticultural therapy into a geriatric longterm care facility, p. 61-80. In: S.E. Wells (ed.). Horticultural therapy and the older adult population. Haworth Press, New York.

Mirowsky, J. and C.E. Ross. 1990. Control or defense? Depression and the sense of control over good and bad outcomes. J. Health Soc. Behav. 31:71-86.

Mossey, J.M. and E. Shapiro. 1982. Selfrated health: A predictor of mortality among the elderly. Amer. J. Public Health 72:800-808.

Pearlin, L.I., M.A. Lieberman, E.G. Menaghan, and J.T. Mullan. 1981. The stress process. J. Health Soc. Behav. 22: 337-356.
Predney, M.L. and D. Relf. 2004. Horticulture therapy activities for preschool children, elderly adults and intergenerational groups. Act. Adaptation Aging 28:1-18.

Rappe, E. and S.L. Kivela. 2005. Effects of garden visits on long-term care residents as related to depression. Hort Technology 15:298-303.

Regnier, V. 2003. Design for assisted living: Guidelines for housing the physically and mentally frail. Wiley, Hoboken, NJ.

Ross, C.E. and J. Mirowsky. 2002. Age and the gender gap in the sense of personal control. Social Psychology Qrtly. 65:125-145.

Rothert, E.A. and J.R. Daubert. 1981. Horticultural therapy for nursing homes, senior centers, retirement living. Chicago Hort. Soc., Glencoe, IL.

Rowe, J. and R. Kahn. 1998. Successful aging. Random House, New York.

Schieman, S. and H.A. Turner. 1998. Age, disability, and the sense of mastery. J. Health Soc. Behav. 39:169-186.

Street, D., S. Burge, J. Quadagno, and A. Barrett. 2007. The salience of social relationships for resident well-being in assisted living. J. Gerontol. Soc. Sci. 62B:S129-S134.

Strimple, E.O. 2003. A history of prison inmate-animal interaction programs. Amer. Behavioral Scientist 47:70-78.

Surtees, P.G., N.W.J. Wainwright, R. Luben, K. Khaw, and N.E. Day. 2006. Mastery, sense of coherence, and mortality: Evidence of independent associations from the EPIC-Norfolk prospective cohort study. Health Psychol. 25:102110.

U.S. Department of Health and Human Services. 2006. A profile of older Americans. 12 Oct. 2007. <http://www.aoa. dhhs.gov/prof/Statistics/profile/2006/ 4.asp>.

U.S. Department of Justice. 2002. Reentry trends in the U.S. Bureau of Justice Statistics. I Apr. 2008. <http://www.ojp. usdoj.gov/bjs/reentry/recidivism.htm>.

Willcox, R.T. and R.H. Mattson. 1979. Horticultural therapy maintains life-satisfaction of geriatrics. Great Plains J. Hort. Therapy 1:8-12. 